Revista Iberoamericana, Vol. LXVII, Núm. 197, Octubre-Diciembre 2001, 781-793

\title{
¿EDITORIALES PEQUEÑAS O PEQUEÑAS EDITORIALES?
}

\author{
POR \\ Celina Manzoni \\ Universidad de Buenos Aires
}

Si en el campo cultural argentino se hiciera con cierto detalle una arqueología de la trayectoria realizada por las numerosas editoriales llamadas independientes o alternativas y a veces pequeñas (por sus recursos técnicos y financieros, cantidad de personal, capacidad de distribución, etcétera), se volvería visible una red de tradiciones en cuyas condensaciones podrían leerse de manera sesgada capítulos de una historia cultural, tanto por el papel que desempeñaron en la difusión de nuevos escritores, como por el desarrollo de nuevos públicos e incluso de un público de grandes lectores.

La condición de "pequeñas" no parece haber afectado una audacia visionaria y una persistencia capaz de derrotar no sólo especulaciones pesimistas sino también la contundencia de allanamientos, incendios, presiones y prisiones. De estas pequeñas editoriales de gran literatura se podría decir, parafraseando a don Francisco de Quevedo: “Serán pequeñas mas tendrán sentido”. Editores como Gleizer en los años veinte, la sostenida labor posterior de Claridad, Sur, Losada, Emecé, Fabril, Sudamericana, siguen siendo puntos de referencia en un ambiente a veces afectado por el virus del olvido. Sin embargo, la experiencia de los años sesenta, por su cercanía en el tiempo y por la calidad de los cambios que operó, se convierte en los noventa en un modelo quizá nostálgico pero también estimulante.

Cuando Robert Escarpit anunció en 1965 La revolución del libro, en un texto que retomaba y ampliaba las tesis que R.E. Barker sintetizó en 1956, Books for All, la consigna resultó de inmediato muy cercana a las universidades, entonces uno de los sectores más dinámicos de la cultura argentina; bajo la dirección de Boris Spivacow, Eudeba (Editorial Universitaria de Buenos Aires), la hizo suya, como Libros para todos. El libro se expandió en el espacio de los kioscos, y las ediciones de bolsillo o las ediciones económicas de textos clásicos ilustradas por artistas ya consagrados y a veces emergentes, ocuparon su espacio en bibliotecas familiares tradicionales o en las que entonces se iniciaron. Tras el golpe de Estado de Onganía en 1966, que, entre otras tropelías intervino las universidades provocando el éxodo masivo de profesores y la expulsión de estudiantes, Boris Spivacow creó el Centro Editor de América Latina reformulando lo que había sido el lema de Eudeba: “Más libros para más”, una mayoría en la que se incluían los sectores de público ampliado que, entre otros fenómenos, protagonizaron el denominado boom de la literatura latinoamericana. Una política editorial por la cual se constituyó en uno de los espacios 
ideales de la cultura cuando los nombres de las casas editoras resonaban de manera casi mítica en la imaginación de los jóvenes lectores: Jorge Álvarez, Centro Editor, Galerna, La Rosa Blindada, Pasado y Presente, Fondo de Cultura Económica, Siglo xxi, Alianza.

Desde entonces todo fue muy rápido y en nuestro país, especialmente dramático; la represión fríamente sistemática llevada a cabo por el autodenominado Proceso de Reorganización Nacional desde el golpe militar de 1976, contra escritores, artistas, estudiantes, dirigentes sindicales y militantes políticos de todas las organizaciones, afectó a la industria del libro que también sufrió graves embates. En la entrada de la Feria del Libro de 2001, una instalación titulada "Fuego de libros" (idea de Carlos Alonso y realización de Ariel Mlynarzewicz), recuerda el día de 1980 en que un millón y medio de ejemplares del Centro Editor de América Latina ardió en la tierra baldía de Sarandí, un suburbio de Buenos Aires. Y, con todo, no puede hacerse cargo de los miles de bibliotecas violadas, allanadas, ocultadas, desarticuladas en el cuerpo de sus autores, en el de los lectores, en el de los editores y en el de los mismos libros.

Las modificaciones ocurridas desde entonces produjeron desplazamientos y transiciones, algunas definitivas, de modo tal que no todos sus protagonistas tienen hoy una presencia activa en el campo cultural; sin embargo, otros se mantienen y aparecen nuevos editores que, reincidentes, recuperan o recrean espacios sólo posibles por el ejercicio sostenido de la imaginación. Algunos analistas, aparentemente abrumados por los cambios que se precipitan sobre el mundo del libro, exageran la situación de los pequeños editores: ya los ven absorbidos por los grandes grupos, convertidos ellos y sus empresas apenas en nombres fantasmales, sombras. Exageran, porque algunos de esos apasionados por los libros lograron sobrevivir junto con sus editoras y porque nuevos entusiastas se han sumado a lo que se puede pensar como una inflexión renovada de la tradición editorial argentina.

Una convocatoria a pensar sobre "Mercados, editoriales y difusión de discursos culturales en América Latina” no podía prescindir de una búsqueda, que aun provisoria, recogiera la opinión de los editores, protagonistas de uno de los escenarios del mercado editorial. En esta indagación nos acompañaron Daniel Divinsky de Ediciones de la Flor, José Luis Mangieri de La Rosa Blindada, que en los ochenta con Libros de Tierra Firme encaró un nuevo proyecto, y Manuel Pampín de Corregidor: los históricos. Entre los nuevos, Adriana Astutti y Sandra Contreras de la editorial rosarina Beatriz Viterbo, Gastón Gallo de Simurg y Javier Riera de Biblos. Aunque no pudimos incorporar a editoras como Alción de Córdoba o a la ya clásica Último Reino, dirigida por Víctor Redondo, ni a nuevos emprendimientos orientados a un público especializado, los resultados responden a la expectativa inicial de integrar nuevas voces, entre las que incluimos las de algunos libreros jóvenes, la de Danilo Albero, un librero-escritor, y la de una académica, la profesora Susana Romanos del Instituto de Bibliotecología de la Facultad de Filosofía y Letras de la Universidad de Buenos Aires. ${ }^{1}$ Sería deseable una

\footnotetext{
${ }^{1}$ El trabajo se realizó a partir de los elementos recogidos en una indagación a la que la mayoría de las personas consultadas respondió por escrito. Ezequiel De Rosso, joven ayudante de cátedra en la Facultad de Filosofía y Letras y en la Facultad de Ciencias Sociales, realizó valiosas sugerencias y colaboró con inteligencia tanto en la elaboración de las preguntas como en la realización personal de algunas entrevistas.
} 
continuidad que retomara y ampliara en cada uno de los países del continente y también en España, las experiencias todavía dispersas de las pequeñas editoriales a las que algunos prefieren llamar independientes, una categoría de difícil definición.

1. EN EL ORIGEN DE UNA EDITORIAL HAY SIEMPRE UNA CARGA DE FORMACIÓN Y DE DESEO (JAVIER RIERA)

Las directoras de la editorial Beatriz Viterbo, la única dirigida por mujeres, recuperan ese momento en el que "al final de una jornada de estudio de la Teoría Estética de Adorno donde se mostraba el equilibrio precario de la autonomía del arte frente a la industria cultural [surgió] la idea, y el deseo, de generar un espacio en el que pudiéramos ampliar el horizonte de nuestra profesión [...] sin irnos de nuestro país ni de nuestra ciudad”. Sin experiencia previa, Adriana Astutti, Sandra Contreras y Marcela Zanín, fundaron en Rosario en 1990, la editorial que hoy siguen dirigiendo las dos primeras. Una convicción joven, observada con simpatía pero sin demasiadas esperanzas por los más experimentados, similar a la que movilizó a Gastón Gallo convertido en editor, “de un momento a otro”, en 1995, a los veinticuatro años, mientras cursaba la carrera de Letras en la Universidad de Buenos Aires, con un capital inicial que resultó de la venta de las primeras ediciones de Bioy Casares atesoradas en su biblioteca. "Sin tradición familiar alguna, el gesto inicial [...] fue el de compartir con otros el deslumbramiento por un escritor argentino olvidado: el Vizconde de Lascano Tegui”. Así, De la elegancia mientras se duerme fue el primer título de Simurg.

En otro momento histórico, Javier Riera y su socio Ricardo Grinberg sintieron que armaban "un huequito en medio del espanto" cuando en 1976, vendiendo también sus libros personales como usados, realizaron un capital con el cual en 1979 publicaron, con una intención editorial que después se fue desarrollando, el primer título de Biblos: Tales, Anaximandro y Anaxímenes, una colección de fragmentos de filosofía antigua en edición bilingüe.

Los comienzos de Corregidor fueron muy diferentes; Manuel Pampín, en otro rubro de la industria, el de la distribución, conoció en la década del sesenta a dos grandes editores: Juan Grijalbo y Carlos Barral. La oportunidad de conectarse a un mundo que hoy sigue considerando “maravilloso", se la ofreció Barral cuando le propuso co-editar su catálogo que entonces incluía entre otras celebridades a Alejo Carpentier, Raymond Chandler, García Márquez y Vargas Llosa.

José Luis Mangieri, por su parte, en 1962, quiso editar su propio libro de poesía junto con Broccato, un poeta y ensayista fallecido hace poco, que además era linotipista. En esa época Mangieri trabajaba en Eudeba, con Horacio Achaval y con Spivacow que habían creado entre otras, una colección integrada por cuatro libros breves que se vendían juntos: Serie del Siglo y Medio. "Yo imité esa experiencia y fue increíble: hicimos cuatro libritos, uno de Hugo Acevedo, un poeta mendocino muy bueno, un librito mío, un librito de Broccato y un libro de González Tuñón, La rosa blindada. La colección, en su homenaje se llamó así, y ése fue el nombre que luego le pusimos a la editorial”. Cuatro artistas amigos, Norberto Onofrio, Pablo Obelar, Carlos Gorriarena y Carlos Alonso, ilustraron las tapas de los libros y mediante un sistema de preventa que además incluía una rifa de 
los dibujos originales, se vendían los cuatro libros. "Hicimos cuatro mil paquetitos, es decir dieciséis mil libros. Y fuimos tan caraduras que los reeditamos. Y la gente vino a decirnos: 'Che, ¿no editan más libritos?' Te juro que fue así la historia. Empezamos a editar y así más o menos me hice editor y como teníamos relaciones, editamos una cantidad enorme de libros y las tiradas eran muy grandes”. Los comienzos de Daniel Divinsky muestran el desarrollo de la misma fascinación. La venta de libros y la dirección de una colección de apuntes jurídicos en el Centro de Estudiantes de la Facultad de Derecho, lo llevaron a la amistad con Jorge Álvarez para quien hizo trabajos de edición. "Y ahí empezó la historia, por placer intelectual”. El golpe militar de 1966, la "Noche de los bastones largos”, lo encontró cursando el posgrado en Sociología: "se acabó la carrera y entonces busqué otra salida, que después, en 1973, se convirtió en actividad exclusiva”. Con una inversión inicial de trescientos dólares repartidos en cuatro libros: una antología sobre la ciudad, Buenos Aires, de la fundación a la angustia, "nos equivocamos en el tiraje y todavía hay; treinta y cuatro años después se vende a un peso en la Feria del Libro", después autores importantes pero muy difundidos, Paul Nizan, Georges Brassens: "Y ahí empezó la cosa”.

La profesionalización se produce en 1970 cuando Quino corta la relación con Jorge Álvarez y empieza a editar con Ediciones de la Flor. "Yo me ganaba la vida como abogado así que el criterio era el gusto, absolutamente. Publiqué poesía de Tennesse Williams y de LeRoi Jones, hacía lo que me daba la gana”. Es un período de gran apetencia por la innovación que se corta en 1976; "en el '77 nos meten presos y nos vamos”; la editorial se mantiene con reediciones y a finales del '83, "cuando vuelvo, hay un año y medio todavía, en el que hago también lo que se me da la gana. A partir de entonces se acabó: hago lo que puedo".

\section{La globalización provincializó el libro argentino (Danilo Albero)}

La proliferación de grandes concentraciones empresarias internacionales que adquirieron editoriales de larga tradición (Sudamericana por Bertelsmann y Emecé por Planeta) y que, junto con sus propios sellos, importan ingentes capitales además de instalar sus propias filiales, que por otra parte, no sólo editan sino que controlan puestos de venta estratégicos en un momento de grave recesión económica en la Argentina, ha provocado algunas reflexiones acerca de las posibilidades de inserción de las pequeñas editoriales.

Gastón Gallo piensa que "la concentración de los grupos editores, curiosamente, deja liberado -en relación con la literatura- un campo de acción marginal pero muy interesante a los sellos independientes. Se podría tal vez afirmar que casi no hay competencia entre ambos segmentos sino, más bien, una distribución del mercado claramente dividida; la competencia, en todo caso, se da entre los grandes grupos, por un lado, y entre algunas editoriales independientes, por el otro”. Una opinión que, por lo menos en un aspecto, no comparte Manuel Pampín para quien: "La posibilidad de poder competir con las grandes editoriales argentinas, que en general han sido absorbidas por capitales extranjeros no es nada fácil, dado que ellas tienen como objetivo primordial eliminar a la competencia a partir del control de los espacios de venta directa al público y fundamentalmente, de los medios de comunicación”. 
Algunas de estas diferencias expresan, entre otras cuestiones, perspectivas vinculadas a la historia de la editorial. Daniel Divinsky recuerda que en los años sesenta y setenta, la disponibilidad económica y lo que él llama "cierto esnobismo" unidos a formas de comunicación más vinculadas al "boca a boca” que a los grandes medios, motorizaba la innovación, hasta el punto de que "el más disparatado experimento" tenía una demanda mínima que cubría por lo menos, una parte importante del costo; una situación que se modificó cuando disminuyeron tanto la capacidad económica como el tiempo dedicado al entretenimiento y que recuperó un breve auge entre 1983 y 1984 por la necesidad de información obligada para suplir el aislamiento sufrido durante los años de la dictadura. Según Javier Riera, en el análisis habría que introducir otras variables: al hecho de que en Argentina pueda calcularse una existencia de 5 ó 6 millones de marginados del sistema, se agrega la circunstancia de que quienes sí lo integran y que en parte habrían incrementado su poder adquisitivo, no consideran al libro dentro de sus hábitos de consumo.

Antes de retomar este último aspecto se vuelve necesario poner de relieve la importancia de las políticas del Estado en relación con el libro. La mayoría de los editores coinciden en que las políticas de subvención del Estado y de otras instituciones constituyen una parte del sostén económico de la editorial. Según Mangieri, “una presencia que hay que destacar siempre, es la del Fondo Nacional de las Artes que, lo mismo que la Fundación Antorchas, tiene una política crediticia, concursos, subsidios y créditos en todas las áreas”. En otras variantes, los editores a veces pagan de su propio bolsillo toda la edición de un libro, otras veces la comparten con el autor, y en ocasiones es el autor quien paga la edición a través de diversas formas de crédito. Astutti y Contreras consideran que el apoyo estatal o institucional es importante aunque no decisivo. Según Divinsky, para ciertos libros, cuya tirada es chica y su valor indiscutible, la única posibilidad de edición suele ser la compra por la Comisión Nacional de Bibliotecas Populares que, "manejada con criterios bastante profesionales y no discriminatorios", cuenta con fondos provenientes de un porcentaje de la lotería lo que ha permitido, por una parte, que las Bibliotecas Populares estén bien provistas y por otra, que de las 50 editoriales convocadas, entre 35 y 38 fueran chicas. Pampín considera que como respuesta a las actuales prácticas monopólicas debería existir una protección para el libro de autor argentino e impreso en el país.

A estas alturas, Javier Riera formula una de las paradojas de la globalización en relación con los modos de operar de las multinacionales en la industria del libro; una gran editorial instalada en Argentina por ejemplo, publica autores argentinos sólo para Argentina y una filial del mismo sello hace lo mismo en Chile con autores chilenos pero no los distribuye de modo que se realice un “cruce de fronteras”. Pablo Pazos, como librero, piensa que “esa política además de expresar desinterés por la difusión cultural, en el largo plazo implica criterios erróneos de mercado”. En otra flexión del tema percibe que, salvo en casos aislados, "no existe una conciencia orientada a crear o, eventualmente, a explotar un mercado potencial, el de la literatura hispanoamericana”.

Desde otro perfil, que en cierto sentido complementa lo que se venía diciendo, Daniel Divinsky reconoce que Ediciones de la Flor compensó la baja de las ventas en Argentina con lo que vendió en Latinoamérica, no porque la situación económica sea mejor en otros lugares sino porque en el conjunto se logra un relativo equilibrio. Los libros de Quino: A 
mí no me grite, Todo Mafalda y Mafalda inédita, lo mismo que los de Fontanarrosa, se vendieron en Venezuela, México, Uruguay, Chile y Puerto Rico, donde algunos de sus títulos tienen salida continua. En otra línea tuvo una experiencia similar con libros de ensayo traducidos, como La religión, un diálogo entre Gianni Vattimo y Jacques Derrida, y con un par de libros que entraron al sistema de educación bilingüe en las zonas hispanoparlantes de los Estados Unidos donde se venden regularmente y bien.

Para Beatriz Viterbo las conexiones con América Latina, al revés de lo que sucede con librerías o bibliotecarios de Estados Unidos o de Europa, son dificilísimas. La asistencia al I Encuentro de Editores Independientes que tuvo lugar en Gijón, España, en mayo de 2000, le permitió establecer contacto, por primera vez, con otras pequeñas editoriales latinoamericanas: Trilce, de Uruguay; Era, de México; Lom y Cuarto Propio, de Chile. De allí surgió la necesidad de estrechar relaciones a través de co-ediciones o de intercambio de catálogos que favorezcan la distribución en un ámbito en el que no existen o se desconocen redes de distribución, por lo que su signo suele ser la discontinuidad.

Javier Riera ve con interés el desarrollo de un gran movimiento de ferias latinoamericanas: SILAR, cuya sede va rotando todos los años, las importantes ferias de Buenos Aires y de Guadalajara y otras que se realizan en casi todas las ciudades de América Latina. Aunque permiten que los libreros, los editores y los autores se desplacen, no logran quebrar el hecho de que los mercados siguen siendo nacionales y locales. Un problema para el que parece haber elaborado una respuesta la muy reciente creación de Edit.Ar que agrupa a nueve editoriales pequeñas con la idea de "potenciar los recursos de cada uno de sus integrantes para bajar los costos, lograr una mayor eficiencia y ser más competitivos" (La Nación, Buenos Aires, 22 de mayo de 2001; Sección 5 “Comercio Exterior”16).

Estos y otros movimientos corroboran una expectativa de recuperar en nuevas y difíciles condiciones, un momento en que el libro argentino se exportaba a otros países del continente. Danilo Albero trae al diálogo el recuerdo de los años juveniles de García Márquez: “Además había un amigo librero al que ayudábamos a hacer los pedidos. Cada vez que llegaba una caja de libros de Buenos Aires hacíamos una fiesta. Eran los libros de Sudamericana, de Losada, de Sur. Aquellas cosas magníficas que traducían los amigos de Borges”.

\section{Son libros que necesitan y deben Ser editados (Beatriz Viterbo)}

La pérdida de hábitos de lectura, de fuerte incidencia en el panorama general, conduce a dos problemas relacionados entre sí: los criterios de selección de títulos y la consideración de la importancia de la figura del librero, otra tradición que parecería en decadencia.

Los criterios de selección estarían orientados al mantenimiento y eventualmente al ensanche de los intersticios de que se hablaba antes y a los que se suele llamar "nichos", en los que se refugia la producción de las editoriales pequeñas. Beatriz Viterbo asegura que sus criterios de selección "no ha[n] tenido nunca como principal objetivo el rendimiento comercial, [sino] lo que podríamos llamar, amplia y simplemente, el 'gusto'”. Así fue que la editorial empezó con César Aira, el autor que en sus comienzos, en los años noventa, estaban descubriendo. Reconocen que la rentabilidad es un factor que se debe 
promover para que el sello pueda seguir funcionando, pero aun en los casos en que es escasa o incluso nula, "estamos convencidas de que son libros que necesitan y deben ser editados, por la sencilla e insoslayable razón de que son signos de la producción crítica, intelectual, del momento”. Con esta política, procuraron la creación de un espacio, materializado en un catálogo: “crear catálogo, hacerlo crecer, difundirlo cada vez más, asegurarle una recepción de la crítica. Creemos que vale la pena”.

José Luis Mangieri también es terminante en este sentido. Aunque "no se siente un genio" por editar los libros con que retoma La Rosa Blindada: La estrategia de la clase obrera de Nicolás Iñigo Carrera que estudia la huelga general de 1936 en solidaridad con los obreros de la construcción, Memorias de un ferroviario y otros, sabe que "esos libros tienen que estar presentes". Para Simurg, una editorial de literatura, "el criterio es, básicamente, de orden estético; el gusto personal priva por sobre otros intereses cuando se realiza la selección de originales”. El hecho de que, en opinión de su editor, exista un limitado espectro de lectura para la ficción nacional, se refleja en el ámbito de las tiradas y conduce a la opción por un catálogo manejable y un público reconocible.

Otros editores consideran que la rentabilidad sigue siendo un valor a tener en cuenta a la hora de publicar sus libros. Javier Riera es terminante: "Uno puede editar una cantidad muy limitada de libros por amor al libro pero la actividad tiene que ser lucrativa para garantizar la continuidad; el primer objetivo es la supervivencia”. Divinsky sugiere que una forma de asegurar esa continuidad consiste en que los criterios de selección pasen a veces por recurrir a lo conocido: aquello que fue efectivo y lo sigue siendo. En otros términos, ante situaciones de riesgo, prefiere no innovar: "Lo que le queda a las editoriales independientes, medianas, PYMES (Pequeñas y Medianas Empresas), es mantenerse en su nicho de mercado, no excederlo". Es consciente de no estar en condiciones de competir con un best-seller; aunque pudiera pagarlo tampoco tendría la capacidad de tirada ni de distribución necesarias.

La misma idea del nicho es expresada con eficacia por Manuel Pampín: ”Las pequeñas editoriales sólo podrán subsistir en un mercado globalizado y excesivamente monopolizado por las grandes empresas publicando autores poco conocidos y temas descuidados por los grandes editores, por tratarse de 'espacios' reducidos que tienen que ver con el rescate cultural de determinado país, o área del continente”.

Si las grandes editoras multinacionales instaladas en el país apuntan a retornos rápidos sin tener en cuenta que el mercado del libro es un mercado a largo plazo, y que la falta de diferenciación del libro como mercancía cultural determina políticas riesgosas, una de las consecuencias es que, "salvo raras excepciones, en el país no tienen catálogo, cada tres o cuatro años liquidan como saldo su fondo editorial y raramente reeditan”, dice Danilo Albero ratificando lo que constituye una zona de fuerte diferenciación entre grandes y pequeñas empresas.

Entre otros rasgos, entonces, el llamado nicho de las editoriales chicas se define por una serie de estrategias en relación con la formación del catálogo. Para Javier Riera, el objetivo de una editorial como Biblos, enfocada principalmente a la filosofía, la historia, la antropología, la semiología y el ensayo cultural, es tratar de constituir un fondo que pase también por lograr un libro de divulgación académica que conjugue alto nivel y accesibilidad. No obstante, reconoce que sigue siendo difícil acercar estos libros a mayor número de 
lectores: de los cuarenta o cincuenta títulos nuevos por año, si se incluyen las reediciones, el editor tiene que buscar un tránsito hacia su público y eso es muy difícil de sostener: “desearíamos acompañar más el recorrido de cada uno de nuestros títulos hacia el lector, pero, lamentablemente, no se puede hacer todo lo que querríamos”.

La editorial Ediciones de la Flor sostiene que "una editorial anda bien cuando se puede mantener con el fondo editorial, lo ideal es que si se dejan de publicar novedades durante un tiempo, no se note una carencia”. En este caso, la experiencia del catálogo es fundamental porque una editorial chica no necesita reemplazar los libros todos los meses ya que se venden más lentamente, pero en forma constante. El mantenimiento del fondo editorial depende también de lo que el mismo Divinsky llama "la lealtad” de sus autores: Quino, Fontanarrosa, Caloi. Una reflexión que propone de manera sesgada, una paradoja: el caso de editoriales pequeñas que realizan el gesto inicial de riesgo y “descubrimiento”, que en una etapa posterior es usufructuado por los grandes grupos. Juan Gelman, Andrés Rivera, publicados por primera vez por La Rosa Blindada, y Rodolfo Walsh por Ediciones de la Flor entraron luego en el circuito de las grandes editoriales aunque los herederos de Walsh volvieron rápidamente a los orígenes después de una experiencia poco convincente. Por lo que hemos podido recoger, aun en el marco de las grandes concentraciones y de la crisis económica, en Argentina las editoriales pequeñas e independientes se mantienen e incluso crecen. Un posible intento de definición acerca de qué se entiende por "editorial pequeña e independiente” conduce a la consideración de dos factores sintetizados por Beatriz Viterbo: "una editorial que no dependa de un grupo multinacional, pero sobre todo que pueda construir su catálogo con autonomía”. El hecho de que muchos de los libros se editen, en casi todos los casos, con el aporte del autor o con subsidios institucionales, podría aparecer cuestionando el carácter “independiente”, una disyuntiva que no sería tal en tanto el carácter de independencia no pase por criterios exclusivamente económicos sino por la voluntad de construir y sostener un catálogo que no tendría inserción en otro espacio editorial. Se sabe que el abandono o el debilitamiento de un criterio riguroso de selección, puede conducir a la pérdida o disminución de un prestigio a veces duramente conseguido.

La ventaja de una estrategia basada en el catálogo, en la calidad de un fondo editorial que asegura la permanencia de los títulos, consiste en que ante una situación de crisis económica, las editoriales más chicas, “alternativas”, en palabras de Mangieri, pueden afrontar mejor algunas circunstancias generales como, por ejemplo, la disminución del público lector que según Albero incide de manera mucho más fuerte en el mercado de lo que llama, sin dudar, "libro basura”, que sobre las editoras pequeñas o especializadas.

También Divinsky piensa que en una editorial mediana los efectos de la disminución de público son menores que en una grande, entre otras razones porque no depende de un equipo de producción que rinde en relación con lo que produce ni de un equipo de ventas al cual hay que proveer de novedades. Ilustra su aseveración con un ejemplo: Ediciones de la Flor había planificado publicar 42 títulos nuevos en el año 2000, y aunque sólo pudo publicar 19, no está peor que si hubiera cumplido con todo lo previsto; como contrapartida, reconoce que esa circunstancia "requiere paciencia de los autores, tienen que aceptar que los libros salgan con mucha demora, pero lo hacen porque saben que es una manera posible de funcionar”. 
Pensando en el futuro, tanto Mangieri como Pampín tienen entre otros proyectos, la idea de publicar una revista. En el caso de Pampín se trataría de relanzar la segunda etapa de la Revista Latinoamericana, una publicación orientada a dar a conocer la literatura de nuestro continente y de la que sólo salieron cuatro números. Mangieri imagina una revista que además de publicar poesía, incluya ensayos, traducciones, y que se regale a los libreros con el compromiso de que impulsen la venta de poesía: "es un asunto de imaginación y contra la imaginación creadora no se puede”.

\section{Las librerías eRAn lugares de encuentro (José Luis Mangieri)}

Al retomar cuestiones como el cambio de los hábitos de consumo, la disminución o estancamiento del círculo de los grandes lectores (“todos peinan canas”, según Divinsky), junto con el tema del catálogo y la delineación de perfiles propios, reaparece un aspecto que merecería titulares en letra catástrofe: la desaparición de la figura del librero, entendido en palabras de Mangieri como aquel con quien se compartía un espacio: "Y bueno, el librero que conocí yo... y sí, desaparece; libreros como Damián Carlos Hernández, un tipo al que hay que hacerle un monumento, como Héctor Yánover de la librería Norte, creaban lugares donde uno no iba a perder el tiempo. Me acuerdo que con Tuñón nos veíamos en la librería Norte, íbamos a tomar un café, venía Horacio Salas; eran lugares de encuentro, había más ocio, quizá había más tiempo, hoy va todo a una velocidad vertiginosa, un poco al divino botón, pero todo es más rápido. Y el librero sabía”. La figura del librero-lector y muchas veces también escritor, tan entrañable para muchos, se ve reemplazada por vendedores que, no sólo desconocen el universo de los libros sino que también, como señala Gastón Gallo, a veces, confunden los términos comerciales: "suelen dar por 'agotados', sin más, libros que simplemente no tienen en ese momento en stock”. Pablo Pazos piensa que el deterioro de la profesión de librero está en relación con un criterio más ideológico que económico. Sería un proceso iniciado con la llegada a la comercialización del libro de capitales ajenos al sector; el imperio de un modo de comercialización que no distingue entre un libro y cualquier otro producto del mercado. La preocupación por la pérdida de la relación entre el librero y el lector, como la que todavía mantienen por ejemplo en Buenos Aires, Héctor Yánover, Guillermo Dávalos, Pedro Wolkowicks, Claudio Armengol, y entre los más jóvenes Pablo Pazos, Jorge Sreitag y Esteban Sauer, que hoy son excepción, es compartida por las directoras de Beatriz Viterbo para quienes la figura del librero ha sido un gran apoyo en su proyecto editorial.

Para algunos de los entrevistados, la solución radicaría en la elaboración de políticas estatales adecuadas. Según explica Divinsky: "Es inevitable que desaparezca el librero si no se sanciona la Ley de Precio Único del Libro, que prohíbe que las casas que venden libros hagan un descuento mayor del diez por ciento sobre el precio fijado por el editor". Si las grandes superficies, como los supermercados, tienen sólo los libros que se venden mucho, y los venden con descuentos especiales, al librero sólo le quedan los libros que se venden poco, y con eso no sobrevive.

En el caso de los libros de poesía, Mangieri recuerda la segunda experiencia de La Rosa Blindada en los sesenta, con España a tres voces de Marcos Ana, Luis Alberto Quesada y Jesús López Pacheco, del que se hicieron cinco mil ejemplares y que se reeditó. 
Su afirmación de que los medios no gravitan, por lo menos en la venta de poesía, lo lleva a preguntarse por el misterio que encierra el hecho de que a pesar de todo, esos libros sigan circulando: "Yo siempre digo una cosa y es cierta: el libro de poesía no se compra, se roba o se presta”. Una afirmación tan heterodoxa se sustenta en parte en su convicción de que el libro de poesía circula de mano en mano, siguiendo itinerarios casi secretos que incluyen además los libreros que los conocen y los nombres de las librerías en las que se los vende. En relación con el segmento de la poesía, Mangieri recupera un rasgo que, según él, existe entre los poetas y sobre todo entre las editoriales de poesía: “es que el género poético genera una red solidaria que yo no sé de dónde viene, porque han sido tan golpeados, o porque no les hacen caso... y de ahí viene la solidaridad de los 'humillados y ofendidos'; por eso los jóvenes poetas tienen lugares a los que acudir”.

En este marco, la promoción del libro y las relaciones con la prensa escrita o eventualmente televisiva, merecen diversas opiniones, desde las que manifiestan descreimiento en el valor de los comentarios, por lo menos en relación con los libros de literatura, a los que perciben la dificultad de competir con los poderosos servicios de prensa de las grandes editoriales. Con escasas excepciones, las editoras independientes no confían el destino de sus libros a los medios habituales, una situación que expresa probablemente lo que algunos no vacilan en calificar como pérdida de idoneidad de lo que en términos generales se denomina periodismo cultural.

5. LA NUEVA ERA DE LAS COMUNICACIONES NO SERÁ LA MUERTE DE LA CULTURA ESCRITA (MANUEL PAMPIN)

Como resultado de los avances en el software tanto para edición como para comercialización, se han abaratado los costos, se han diversificado las posibilidades y resulta posible editar muchos más títulos que hace diez años, también ha mejorado mucho la tecnología gráfica disminuyendo los costos de imprenta. Una combinación de factores que unida al crecimiento de la población universitaria, a la altísima diversificación de las carreras y al desarrollo de los estudios de posgrado permite que todos los años se lancen al mercado para ese sector, miles de títulos en tiradas pequeñas: cada vez hay más libros para segmentos más sesgados del mercado.

En general, los cambios tecnológicos no se constituyen en un fantasma del editor; a Daniel Divinsky no lo desvela la posibilidad de que las nuevas tecnologías reemplacen al libro tal como lo conocemos; no obstante, está estudiando la posibilidad de realizar futuras ediciones en formato magnético, algo que todavía no resulta rentable aunque quizá pueda serlo en el futuro. Sintetiza: "De la misma manera que la televisión no eliminó al cine, ni el cine al teatro, el libro va a subsistir y convivir con el formato electrónico”. Una opinión coincidente con la de Manuel Pampín: “creo que el libro impreso no desaparecerá jamás ya que el placer de leer un libro no puede ser superado por el soporte electrónico u otros mecanismos similares. Habrá en el futuro una coexistencia, lógica y necesaria. La nueva era de las comunicaciones no será la muerte de la cultura escrita”.

Tampoco Danilo Albero imagina que el libro en soporte electrónico pueda reemplazar al libro convencional, pero reconoce que "Internet y las enciclopedias en CD-ROM llevan a cualquier usuario posibilidades de consulta y de lectura de obras muchas veces 
inaccesibles en bibliotecas. Esto en zonas de escasos recursos puede ser un incentivo para el libro, la lectura y la cultura escrita, no su rival”. Una opinión proveniente del campo académico, la de la profesora Susana Romanos, ratifica la noción de que el libro puede presentarse en diferentes soportes: papel, electrónico, microforma o dispositivos de audición. En cuanto al debate acerca del posible reemplazo del soporte papel por el electrónico, cree que no se producirá aunque sí percibe las ventajas del soporte electrónico para obras de referencia o de consulta: "la capacidad de almacenamiento, la multiplicidad de puntos de acceso, el poder combinatorio en formas más complejas y específicas, y la velocidad de recuperación juegan a favor de las representaciones electrónicas”.

Riera cree que intelectuales y editores deben pensar y repensar mucho en este proceso. Por una parte percibe que hay que adecuarse a las reglas de juego aunque hoy no se pueda saber si el libro en soporte papel va a ser reemplazado por el libro electrónico virtual. En el futuro pesa también lo que llama "el factor generacional”, un aspecto en el que "se está librando una lucha de fondo". En el terreno educativo le preocupa una tendencia muy fuerte orientada hacia el uso de la computadora como reemplazo y no como complemento. Pero sobre todo percibe que en líneas generales existe una gran confusión tanto en lo que se refiere al uso de Internet, como en la definición de qué se entiende por publicaciones virtuales. Por su experiencia, muchas veces se trata de una fórmula que oculta un mero plagio virtual de material previamente impreso. "De ese modo se pierde todo el trabajo que hay detrás de un libro, se pasa por encima del proceso criterioso y contractual que culmina en la publicación de un libro”. Observa que la escritura, lo mismo que la música y el cine, es un producto especial para su divulgación en Internet pero mientras que en otro tipo de compras el fabricante debe enviar materialmente el producto, en el caso del libro, la música y el cine, el producto cabe en los chips, se puede desmaterializar. "En síno está mal que el libro se desmaterialice, pero debemos preguntarnos qué pasa entonces con la creación, con el proceso de administración y organización, con las remuneraciones: lo que antes era el conjunto de funciones del editor". Teme que en un mundo en el que todos editen en Internet, nadie pague por el trabajo intelectual: "la forma libro es la objetivación de un trabajo realizado por varias personas. Cuando ese proceso se desvirtúa y desorganiza, todo ese trabajo desaparece y es como si nunca hubiese habido nadie, como si nunca hubiese habido trabajo. Quizás se trate de una vuelta a la desaparición del autor”. Una preocupación que se relaciona con el juicio que en estos momentos lleva Random House contra un site de Internet y que básicamente procura llegar a una definición del libro en la que es fundamental establecer el alcance de nociones como copyright y derechos de autor.

\section{Uno HA TENido SATISFACCIONES QUe No PASARON POR CAJA (DivinSKY)}

La idea del éxito en los términos en que lo entiende una sociedad ganada por la espectacularidad y el momentáneo relumbrón como sucedáneos de virtudes más sólidas, no parece seducir a estos editores. Si bien en los años sesenta la demanda de éxito tuvo efectos hasta entonces casi desconocidos, e incluso perturbadores, en el mundo de escritores y editores, el cambio de los tiempos ha llevado a una cierta sabiduría. Para Gastón Gallo: “Tal vez una posible definición de éxito, adecuada a las circunstancias 
nacionales, sea la de poder realizar con gusto una actividad elegida voluntariamente y de la que, además, se obtengan los medios materiales para vivir”. Javier Riera, por su parte, además de resaltar el carácter "pasajero" del éxito, lo vincula con la diferencia de expectativas que se dan entre las grandes editoriales y los pequeños editores; así reanuda la reflexión sobre aspectos vinculados al catálogo y a la velocidad de rotación de los textos. "La editorial chica, por ahora al menos, puede manejarse con tiempos más largos, quizá no con todo su catálogo pero sí con una parte considerable de él. Si yo publico La física de Aristóteles, no puedo pensar de antemano que la saldaré en dos años”. Porque su concepción, como la de los otros editores es diferente, puede recordar que cuando su editorial publicó El fragmento preliminar a la filosofía del derecho de Juan Bautista Alberdi, con un prólogo muy elaborado y notas muy cuidadas de Ricardo Grinberg, durante los primeros dos años casi no se vendieron ejemplares, luego, cuando la edición empezó a circular entre los especialistas y los estudiantes de Pensamiento Argentino, se agotó. Para los parámetros de una editorial pequeña fue un éxito, en los términos de Riera, "porque algo que no existía y que no generaba ninguna expectativa fue, en el largo plazo, reconocido, aceptado y agradecido”.

Un razonamiento similar al que motiva a Simurg cuando recuerda que la edición de algunos textos de Roberto Arlt, inéditos hasta entonces como libro: El resorte secreto y otras páginas y En el país del viento. Viaje a la Patagonia (1934), superó sus expectativas iniciales de venta, pero sobre todo cuando recupera el gesto que significó la publicación de Los sorias de Alberto Laiseca, con prólogo de Ricardo Piglia y diseño de tapa de Guillermo Kuitca. "Siendo una novela de más de mil trescientas páginas y a un precio sideral para el mercado argentino, ciento cuarenta dólares, prácticamente agotó la tirada de trescientos cincuenta ejemplares”.

En otra flexión de las experiencias recogidas, Manuel Pampín, cuyos inicios, además de auspiciosos, alcanzaron en los años sesenta verdaderos éxitos masivos con la venta de más de 50.000 ejemplares de Ceremonia secreta y de Rosaura a las diez de Marco Denevi, recuerda que de inmediato se encontró editando a Macedonio Fernández, Juan Carlos Onetti, Clarice Lispector, Ángel Rama y David Viñas, además de lanzar a los que en ese entonces eran nuevos escritores: Osvaldo Soriano, Haroldo Conti, Juan Gelman, Héctor Lastra, Bernardo Kordon. En esa misma línea de búsqueda creó la Biblioteca de Poesía, iniciada y dirigida por Aldo Pellegrini, en la que se publicaron poemas de George Trakl, Williams Carlos Williams, T.S. Eliot, Dylan Thomas, Robert Frost, Constantinos Kavafis, Odysseas Elytis, Olga Orozco, Manuel Castilla, Alberto Girri, Miguel Arteche, Vicente Huidobro, Alejandra Pizarnik, Enrique Molina, Ricardo Molinari, entre otros. Una apuesta a la poesía que renueva en 2001 con el lanzamiento para la Feria Internacional del Libro de Buenos Aires de la Obra Completa de Susana Thénon.

El amplio catálogo de Corregidor también incluye libros de política y de historia, de teatro, cine, folklore latinoamericano, ensayo y crítica; “espacios que aún, y afortunadamente, no han sido ‘colonizados’ por los grandes grupos extranjeros”. Tampoco su idea de un éxito editorial coincide con la de una empresa "fabricante de libros”; para una editorial que trabaja con la pasión por el libro, es tan importante el libro de éxito como que se agoten varios títulos de poesía, aunque sea en tiradas pequeñas. 
Para esta editorial como para Biblos, un éxito es mantener un título durante treinta años en el catálogo y que el requerimiento de los lectores, aunque no masivo, sea constante; el caso ejemplar para Manuel Pampín es el de Macedonio Fernández, a lo largo de más de dos décadas su editorial ha logrado completar la edición de sus obras. Ambas comparten con Beatriz Viterbo el segmento del ensayo y de la crítica literaria, que en el caso de la última ha llegado a la apertura de un espacio casi inédito, el del libro académico en una variante que integra la Biblioteca Tesis: trabajos de investigación, en general destinados a una suerte de exilio en las bibliotecas universitarias, son recuperados, con algunas variantes, para un público si no masivo, por lo menos ampliado. En su catálogo cuentan como "éxitos", palabra que sus directoras entrecomillan, Cómo me hice monja, Copi, Alejandra Pizarnik, los tres de César Aira. Entre los más vendidos (entre 700 y 1000 ejemplares en tres, cuatro o cinco años), figuran Las culturas de fin de siglo en América Latina, compilado por Josefina Ludmer y Médicos maleantes y maricas de Jorge Salessi; el "placer increíble" de reeditar Las letras de Borges de Sylvia Molloy, o, en el siempre difícil espacio de la poesía, los poemas de Arturo Carrera y de Tamara Kamenszain. Su idea del éxito, como en otros editores de ensayo, radica en que muchos de sus libros se han convertido en textos de referencia: citados en trabajos críticos, incluidos en programas de estudio. Si los tres tomos de obras de teatro y guiones inéditos de Manuel Puig no fueron un éxito de ventas, entran en la categoría de la que también se enorgullecen los otros editores: "sin duda, un sueño cumplido".

Los éxitos inmediatos en la publicación de poesía caracterizaron a La Rosa Blindada en los años sesenta, que tuvo iniciativas novedosas, además de los libros incorporaban la voz de los autores diciendo sus poesías (Nicolás Guillén, Juan Gelman con el Tata Cedrón), la música y el canto de Bola de Nieve, las óperas de Brecht, y la revista La rosa blindada cuyo primer número tuvo una tirada de 10.000 ejemplares. En otra vertiente, libros de política sobre Vietnam, escritos del Che Guevara y clásicos hoy inhallables como Lucha de calles, lucha de clases fueron pioneros entonces, aunque Mangieri opta por la modestia: "Más o menos estábamos con la época. El mérito fue de la época más que de nosotros; la época nos empujaba”.

En narrativa, Divinsky considera un éxito, aunque no un gran suceso, según parámetros a los que no adhiere, "ya que el editor tiene una función social”, haberse adelantado a Alfaguara con la publicación de Cada vez que decimos adiós de John Berger, un libro que vendió 3000 ejemplares en dos años y medio. Quino, Fontanarrosa, Walsh y Caloi son sus autores estrella aunque el libro que más le gusta de su fondo editorial, que tuvo dos ediciones, y que ahora va a tratar de recuperar, es Johnny cogió su fusil, de Dalton Trumbo. Se enorgullece de haber publicado a Boris Vian antes que nadie (Vercoquin y el Plancton, La espuma de los días, El arrancacorazones), la primera edición en castellano de Impresiones de África de Raymond Roussel, Opio de Cocteau, los poemas de Paul Eluard y los de Breton: "Uno ha tenido satisfacciones que no pasaron por caja”.

Como conclusión provisoria de la indagación, se podría decir que estos editores absorbidos por una vocación convertida en oficio, lejos de aparecer como especies en extinción, han mostrado que la capacidad de aprender del pasado va unida a la convicción de que lo mejor está sin embargo, por delante. Que no es poco. 